\title{
Iron Deficiency Anemia in Pregnancy: Can We eradicate?
}

\author{
${ }^{1}$ Atul Munshi, ${ }^{2}$ Sujal Munshi
}

\begin{abstract}
Iron deficiency anemia (IDA) is the most common type of anemia. Most of the anemic patients, especially women, suffer from mild to severe deficiency of iron. Almost $50 \%$ of all pregnant women experience IDA during their pregnancies, and at least 1 out of 5 of girls and women may experience it during their reproductive years. One complete eradication of IDA is not feasible but a try can help us on a long way. Only supplementation is not the answer. Going to the root cause, finding out current situation and managing accordingly by available resources is the correct answer.
\end{abstract}

Keywords: Anemia, Eradication, Iron deficiency, Pregnancy.

How to cite this article: Munshi A, Munshi S. Iron Deficiency Anemia in Pregnancy: Can We eradicate? World J Anemia 2017;1(2):36-39.

\section{Source of support: Nil}

Conflict of interest: None

\section{INTRODUCTION}

Iron deficiency anemia is the most common type of anemia. Most of the anemic patients, especially women, suffer from mild to severe deficiency of iron. The hemoglobin $(\mathrm{Hb})$ count in most adolescent girls in India is less than $12 \mathrm{~g} / \mathrm{dL}$. Most IDA-inflicted people include young children, pregnant women, and menstruating girls and women. Almost $50 \%$ of all pregnant women experience IDA during their pregnancies, and at least one out of five girls and women may experience it during their reproductive years. ${ }^{1}$

\section{ANEMIA IN PREGNANCY}

Both red blood cell (RBC) mass and plasma volume expand from the 1st trimester of pregnancy. Maternal $\mathrm{Hb}$ levels reach a nadir near the end of the 2nd trimester (i.e., diminish by approximately $5 \mathrm{~g} / \mathrm{L}$ ). The plasma expands about 30 to $40 \%$ in volume, which exceeds the

\footnotetext{
1,2Director

1,2Department of Obstetrics and Gynecology, Munshi Group of Hospitals, Ahmedabad, Gujarat, India

Corresponding Author: Atul Munshi, Director, Department of Obstetrics and Gynecology, Munshi Group of Hospitals Ahmedabad, Gujarat, India, Phone: +919824021000, e-mail: munshiap@gmail.com
}

20 to $25 \%$ increase in RBC mass. Thus, there is a dilutional drop in $\mathrm{Hb}$ concentration, which promotes oxygen transport to the tissues including the placenta. Thus, it is no surprise that the physiological iron requirements are three times higher in pregnancy than they are in menstruating women, with increasing demand as pregnancy advances. ${ }^{2}$

About $1000 \mathrm{mg}$ of iron is required during pregnancy, out of which 500 to $600 \mathrm{mg}$ is required for RBC expansion, $300 \mathrm{mg}$ for fetus and placenta, and the rest is utilized for the growing uterus. The prevalence of amenorrhea during pregnancy saves about $150 \mathrm{mg}$ of iron, and therefore, about $850 \mathrm{mg}$ of extra iron is required. Even then, about $500 \mathrm{mg}$ of iron gets depleted, which cannot be replenished through diet alone. If iron stores are already deficient, then IDA, the most common type of anemia in pregnancy, manifests. ${ }^{3}$ Figure 1 shows the reasons of anemia and Table 1 shows the impact of anemia on mother and fetus.

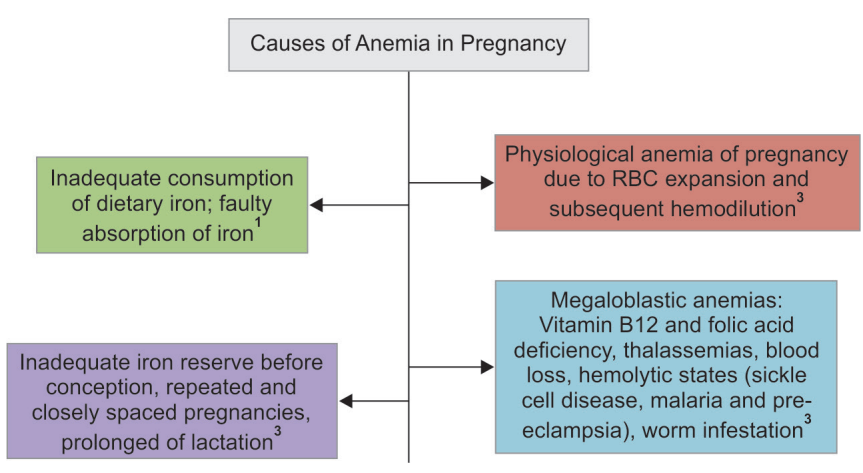

Fig. 1: Causes of anemia in pregnancy

Table 1: Impact of anemia on pregnancy outcomes

\begin{tabular}{llll}
\hline Moderate anemia & & Severe anemia \\
\hline $\begin{array}{l}\text { Maternal } \\
\text { effects }\end{array}$ & $\begin{array}{l}\text { Weakness } \\
\text { Fatigue } \\
\text { Poor work } \\
\text { performance }\end{array}$ & $\begin{array}{l}\text { Maternal } \\
\text { effects }\end{array}$ & $\begin{array}{l}\text { Palpitations and } \\
\text { breathlessness }\end{array}$ \\
& & Tachycardia \\
& & $\begin{array}{l}\text { Cardiac stress } \\
\text { Increased incidence } \\
\text { of preterm labor, } \\
\text { preeclampsia, sepsis } \\
\end{array}$ \\
& & Fecreased iron stores \\
& outcomes & Small-for-gestational-age \\
& & Increased incidence of \\
& & \\
& &
\end{tabular}


Table 2: Problems faced in eradication and how we are failing

\begin{tabular}{ll}
\hline Lack of focus on the underlying & $\begin{array}{l}\text { Poor testing and treatment } \\
\text { causes }\end{array}$ \\
fackilities at hospitals
\end{tabular}

\section{HOW TO ERADICATE ANEMIA?}

Identify problems associated with IDA eradication (Table 2).

\section{Timely Detection of Anemia}

All women require a complete blood examination (CBE) at the first antenatal visit to determine whether anemia, signs of evolving anemia, or features suggestive of a thalassemic syndrome/hemoglobinopathy are apparent (Fig. 2). Repeat CBE at 28 weeks. $^{2}$

\section{Prevention is Better than Cure}

- Twelve by twelve is an initiative aiming to have $\mathrm{Hb}$ of $12 \mathrm{~g} / \mathrm{dL}$ by 12 years of age using prophylactic iron therapy and advising consumption of iron-rich food. $^{3}$

- Deworming: Oral antihelminthic treatment is safe for pregnant and lactating women. Thus, single albendazole (400 mg) or mebendazole (100 mg) doses twice daily for 3 days with iron supplementation should be given to all anemic pregnant women in the second and third trimesters for better results. ${ }^{3}$

- Supplying folic acid tablets from the 1st month of pregnancy.

- Adolescents should be educated about anemia and appropriate nutrition.

\section{Nutrition}

- The recommended daily intake of iron for the latter half of pregnancy is $30 \mathrm{mg}$.

- Absorption of iron increases 3-fold by the 3rd trimester, with iron requirements increasing from 1,2 to $6 \mathrm{mg}$ per $\mathrm{day}^{2}$

- Iron nutritional status depends on long-term iron balance and is favoured by ingestion of adequate amounts of iron in the diet (native or fortified) or through iron supplementation. ${ }^{3}$

- All women should be counseled regarding ${ }^{2}$

- The importance of maintaining adequate iron stores in pregnancy

- Diet in pregnancy including details of iron-rich food sources

- Inhibitors and enhancers of iron absorption

- Dietary diversification: Pregnant women should consume iron-rich foods, such as jaggery, green leafy vegetables like spinach, mustard leaves, turnip green, cereals, and sprouted pulses and cook their food in iron utensils. Too much of cooking should be avoided. $^{3}$

- Food fortification: Fortification of foods with iron aims at improving and sustaining iron nutrition permanently. Iron fortification of common salt can be carried out and has been approved by the Government of India. $^{3}$

- Factors affecting iron absorptionrption are mentioned in Table 3. ${ }^{1,2}$

Table 3: Absorption factors

\begin{tabular}{ll}
\hline Enhancers & Inhibitors \\
\hline Vitamin C & Phytates and other inositol phosphates \\
$\begin{array}{l}\text { Meat, chicken, fish, } \\
\text { certain sea foods }\end{array}$ & Coffee, tea, cocoa, certain spices \\
Fermented vegetables & $\begin{array}{l}\text { Calcium } \\
\text { Soy proteins }\end{array}$ \\
\hline
\end{tabular}

PATHOPHYSIOLOGY $Y^{3,4,5}$
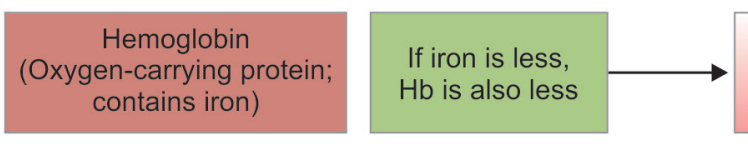

Direct estimation of $\mathrm{Hb}$ gives idea about IDA

Direct estimation of serum ferritin gives idea about ID

1st trimester: $<110 \mathrm{~g} / \mathrm{dL}$

2nd trimester: $<105 \mathrm{~g} / \mathrm{dL}$

3rd trimester: $<100 \mathrm{~g} / \mathrm{dL}$

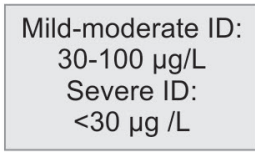

Mild-moderate ID:

Severe ID:

$<30 \mu \mathrm{g} / \mathrm{L}$

Estimation of TIBC or transferrin saturation gives idea about IDA

TIBC in IDA: $170-370 \mathrm{mg} / \mathrm{dL}$

Fig. 2: Progress of Iron deficiency anemia. ID: Iron deficiency; TIBC: Total iron binding capacity 


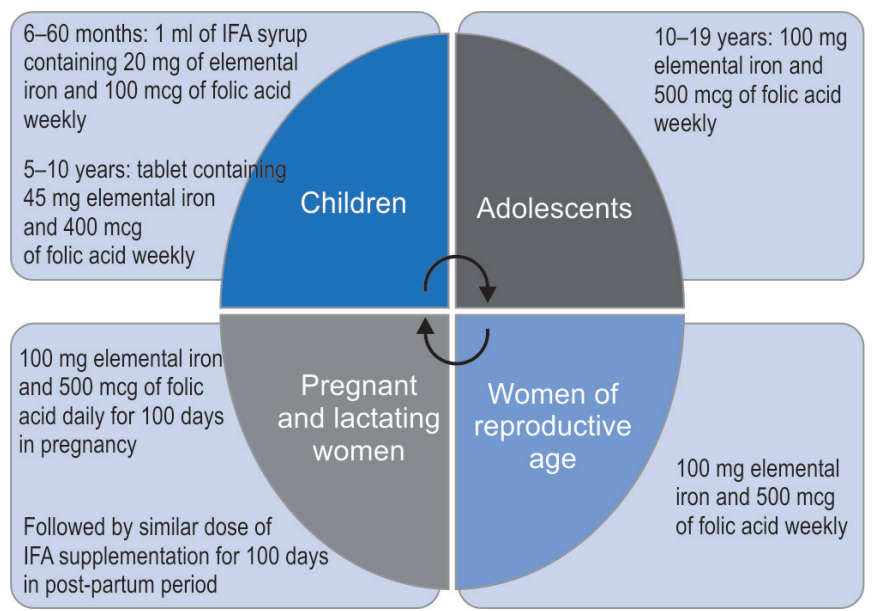

Fig. 3: How much iron at different phases

\begin{tabular}{|l|c|c|}
\hline $\begin{array}{c}\text { Contraindication/intolerance } \\
\text { to oral iron therapy }\end{array}$ & $\begin{array}{c}\text { Noncooperative/defaulter } \\
\text { patient not taking oral iron properly }\end{array}$ & $\begin{array}{c}\text { For a pregnant patient with sev } \\
\text { anemia in the last 8-10 week } \\
\text { of pregnancy }\end{array}$ \\
& \begin{tabular}{c} 
WHEN TO RESORT TO PARENTERAL IRON SUPPLEMENTATION \\
\hline Patients with CRF
\end{tabular} & $\begin{array}{c}\text { Patients on recombinant } \\
\text { erythropoietin therapy }\end{array}$ \\
\hline
\end{tabular}

Fig. 4: Indications and contraindication of parenteral iron

\section{Supplementation}

- Dietary changes alone are insufficient to correct IDA and iron supplements are necessary. ${ }^{2}$

- Figure 3 shows the iron supplementation at different phases

- As most women start their pregnancy with anemia or low iron stores, prevention should start even before pregnancy. As a public health approach, prolonged oral supplementation beginning before the woman becomes pregnant may be a better strategy to benefit the majority of the population. ${ }^{3}$

- Iron supplementation to the mother during pregnancy improves perinatal outcomes, such as the baby's weight, and $\mathrm{Hb}$ level 3 months after birth. ${ }^{3}$

- Oral supplementation

- Dose: $150 \mathrm{mg}$ of elemental iron (750 mg iron salt)

- Oral iron supplements are absorbed better on an empty stomach and are given in divided doses.

- However, oral iron supplements exhibit side effects, such as heartburns, nausea, upper gastrointestinal disturbances, constipation, diarrhea, and teeth stains. Parenteral supplementation

- Blood transfusion with packed cell volume components is carried out only in emergency situations to correct severe anemia. It can restore the $\mathrm{Hb}$ levels rapidly within 48 hours. However, precautionary measures need to be taken in order to reduce the risk of transmission of infections, transfusion reactions (Fig. 4).

\section{CONCLUSION}

Complete eradication of IDA is not feasible but a try can help us a long way. Only supplementation is not the answer. Going to the root cause, finding out current situation and managing accordingly by available resources is the correct answer.

The World Health Organization has recognized IDA in the general population as the most debilitating nutritional deficiency worldwide, noting women to be at particularly high risk. Such a problem, if ignored and not addressed properly, can have a devastating effect on entire populations with serious consequences. The developing world is most vulnerable to IDA. Awareness of the magnitude of the IDA during pregnancy and in nonpregnant females will help health practitioners in recognizing the best methods for diagnosis and treatment, in order to overcome IDA. ${ }^{5}$ The practitioners must focus on building iron stores, increasing patient compatibility of the treatment, prophylaxis of IDA, and utilizing the resources of oral iron, IV iron, and erythropoietin injection resourcefully. 


\section{REFERENCES}

1. Development of Humane Action (DHAN), Eradicate Anaemia-build healthy generations. Available from: http:/ / dhan. org/anaemia/index.php. [cited September 2017].

2. Anaemia in pregnancy - SA Health, Government of South Australia. Available from: http:/ /www.sahealth.sa.gov.au/ wps/wcm/connect/33aa3b804ee1d163abb0afd150ce4f37/ Anaemia+in+pregnancy_27042016.pdf?MOD=AJPERES\&C ACHEID=33aa3b804ee1d163abb0afd150ce4f37. [cited September 2017].
3. Sharma JB, Shankar M. Anemia in pregnancy. JIMSA 2010 Oct-Dec 2010;23(4):253-260.

4. National Heart, Lung and Blood Institute, How Is IronDeficiency Anemia Diagnosed? NHLBI. Available from: https:/ / www.nhlbi.nih.gov/health/health-topics/topics/ ida/diagnosis.

5. Khalafallah AA, Dennis AE. Iron deficiency anaemia in pregnancy and postpartum: pathophysiology and effect of oral versus intravenous iron therapy. J Pregnancy 2012 Jun;2012:630519. 